\title{
The Underpinning Theory of Service Experience's Framework in a Science Centre Setting
}

Norzilawati Md Kamsor, Jasmine Ahmad, Mahadir Ladisma@Awis

To Link this Article: http://dx.doi.org/10.6007/IJARBSS/v11-i6/9968

DOI:10.6007/IJARBSS/v11-i6/9968

Received: 09 April 2021, Revised: 12 May 2021, Accepted: 29 May 2021

Published Online: 17 June 2021

In-Text Citation: (Kamsor et al., 2021)

To Cite this Article: Kamsor, N. M., Ahmad, J., \& Ladisma@Awis, M. (2021). The Underpinning Theory of Service Experience's Framework in a Science Centre Setting. International Journal of Academic Research in Business and Social Sciences, 11(6), 677-688.

\section{Copyright: @ 2021 The Author(s)}

Published by Human Resource Management Academic Research Society (www.hrmars.com)

This article is published under the Creative Commons Attribution (CC BY 4.0) license. Anyone may reproduce, distribute, translate and create derivative works of this article (for both commercial and non-commercial purposes), subject to full attribution to the original publication and authors. The full terms of this license may be seen at: http://creativecommons.org/licences/by/4.0/legalcode

\section{Vol. 11, No. 6, 2021, Pg. 677- 688}

Full Terms \& Conditions of access and use can be found at http://hrmars.com/index.php/pages/detail/publication-ethics 


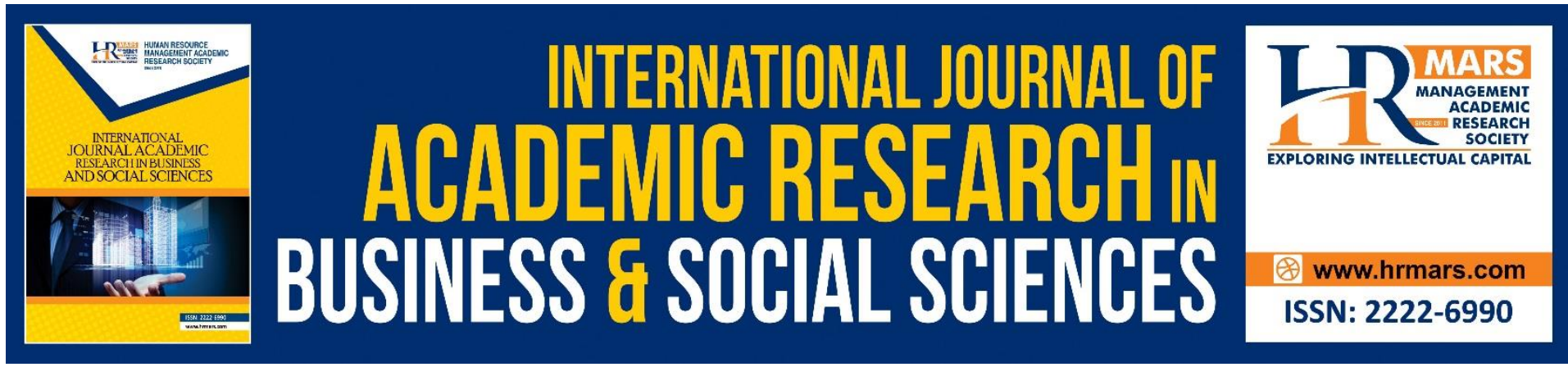

\title{
The Underpinning Theory of Service Experience's Framework in a Science Centre Setting
}

\author{
Norzilawati Md Kamsor \\ Universiti Teknologi MARA (UiTM) \\ Email: norzilawatikamsor@gmail.com \\ Jasmine Ahmad \\ International University of Malaya-Wales \\ Email: profjasmine@iumw.edu.my \\ Mahadir Ladisma@Awis \\ Universiti Teknologi MARA (UiTM) \\ Email: mahadir_ladisma@uitm.edu.my
}

\section{Abstract}

This paper highlights the visitor's service experience (VSE) framework, with its three main dimensions (service delivery, physical and social servicescape), which acts as the stimulus in the environment setting. This relationship theoretically affects the visitor's response (VR) and influences the visitor's approach-avoidance behavioural through the NonFormal Science Learning (NFSL) as a mediator within the primary emotional stage of the pathways. The conceptual framework illustrated the situation with the potential parameters (stimulus) influencing the NSFL and VR. The conceptual framework with the underlying theories is constructed to understand how learners respond to science centres' services, thus continuing to visit the science centres. The public science centre faces great challenges with visitation rates and affordable charges. These challenges further increase as citizens are constantly demanding high-quality services. The theoretical perspective was discussed to understand the possible angle in handling visitation issues and non-formal science learning, with the focus on enlightening service experience among learners.

Keywords: Visitor's Service Experience (VSE), Non-Formal Science Learning (NFSL), Visitor's Response (VR), Science Centre, Underpinning Theory.

\section{Introduction}

Continuous efforts are essential to attract people's interest in Science, Technology and Innovation (STI), especially talent pools, experts, and skilled workers for sustainable development within the new economic trend where the STI is used at its maximum potential. The National Science Centre (NSC) is a public Non-Formal Science Learning (NFSL) institution under the Ministry of Science, Technology, and Innovation (MOSTI), Malaysia, that relates directly to the popularisation and enculturation of STI in the country. It plays a significant role 
in helping the government with the implementation of the National Policy on Science, Technology, and Innovation (NPSTI) 2021-2030, through its Trust Strategic 5 - Strengthening Science, Technology, Innovation, and Economic (STIE) enculturation and applications for Malaysian (MOSTI, 2020). The current NPSTI 2021-2030 has empowered NSC as the centre of excellence for STIE and given them a solid mandate to deliver effective enculturation STI programs amongst Malaysians (MOSTI, 2020). It is a considerable challenge for the government to increase the trust and public's understanding of STI, and it has become even more challenging to find the best approaches on how the public can learn and appreciate STI effectively.

Nonetheless, an international study conducted by a consortium of 17 science centres in 13 countries known as The International Science Centre Impact Study revealed that individuals who visited science centres were significantly correlated with increased: understanding and knowledge of STI; curiosity and interest in STI; engagement and interest with science as a school subject and technology-related out-of-school activities for youth; and personal confidence and identity in STI (Falk, Needham, Dierking \& Prendergast, 2014). The science centres and science museums have a long history in promoting, stimulating interest, and creating awareness about STI. These institutions make science learning more fun and practical and often become great platforms where science is nurtured. They also become excellent avenues for social interaction where similar understandings and beliefs are shared and nurtured into a culture. The science centres, science museums, and other places with similar setting are essential venues for diverse communities to learn and get excited about science because they facilitate science communication, cooperation, engagement, and science activism among the society where they operate (Parker \& Krockover, 2013). Science centres and other similar institutions have asserted their critical roles in cultivating the public understanding and appreciation of science and technology and has been significantly impacted science literacy in greater Los Angeles communities (Falk \& Needham, 2011).

Even though the science centres in STI popularisation and enculturation amongst the society offered great potentials, the institutions face challenges with visitation rates and affordable charges. At the same time, citizens are constantly demanding high-quality services. Therefore, this study highlighted the importance of public science centre and focused on its customer centricity, which is about how the visitor's service experience (VSE) influence the effectiveness of NFSL and potentially affect the visitor's behavioural response after visiting the science centre. Understanding VSE will potentially help the science centre increase its visitation level, reach more people, and gain higher public trust.

\section{The Underpinning Theory}

Examining the main issues of visitation rates, revenue generation, and visitor's demand in the science centre has led us to understand the visitor's approach-avoidance behaviour to the centre. Darwin's 1900 Environmental Psychology Theory, the foundation of the leading Stimulus-Organism-Response (SOR) Model by Mehrabean and Russell (1974), become the primary reference in this study. This underpinning theory is closely related to service delivery and servicescape (physical and social) aspects, acting as the stimulus influencing visitor's approach-avoidance behaviour. The stimulus is a set of characteristics within a service environment that trigger the individual's primary emotional stages (as the organism) and further affect the VR (Loureiro, 2015; Tubillejas-Andrés, Cervera-Taulet, \& Calderón García, 2020). The SOR theory-model usage in explaining the service's domain within the Non-Formal Learning (NFL) places has been highlighted in a few research. Forrest 
(2013) highlighted the SOR framework's application in determining the NFL atmospheres (environments) to understand the influential variables within a museum setting. Hyun et al. (2018) mentioned the SOR theoretical background for explaining the mediation role in millennial's visiting behaviour at a museum.

Darwin's Environmental Psychology Theory originated in the early 1900s when the biologist began developing an ecological theory to investigate how organisms respond in unison to objective stimuli present in the spatially restricted area (Barker, 1968; Rosenbaum \& Massiah, 2011). Later, Barker (1968) and other researchers applied this perspective to the basic SOR model by exploring how people respond to objective stimuli in a spatially bounded consumption setting (Rosenbaum \& Massiah, 2011). The SOR model's basic understanding suggests that people's responses (organism) to the external environment (stimulus) can result in physiological, emotional, and behavioural responses. Figure 1 illustrates the basic SOR model as a fundamental understanding of this theory.

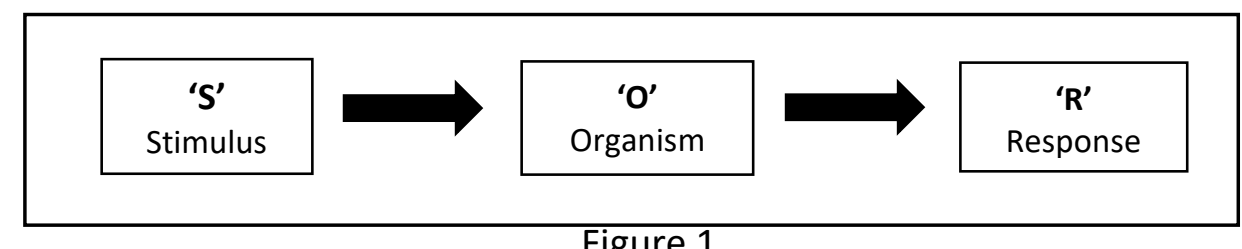

Figure 1

Basic SOR Model

As shown in Figure 1, the model describes how organisms (including employees and customers) respond to environmental stimuli such as temperature, lighting, décor, crowd, and colours representing the organisation's physical servicescape aspect. The environment's setting has a significant influence on the emotional and physiological aspects of the employees and customers, affecting employee's performance and customer's responses to either stay or leave. These conditions relate closely with the visitation at the NSC, where the visitors' experience potentially influences their decisions to either stay longer or leave the premise based on their experiences during the visit. Later, Mehrabian and Russell (1974) expanded the SOR model's understanding by adding the primary emotional response stage, detailing the organism's physiological and emotional phases that lead to the behavioural responses.

Forrest (2013); Barker (1968); Rosenbaum and Massiah (2011) agreed that the most influential theoretical framework for characterising customer responses to the environment is the expanded SOR model developed by Mehrabian and Russell (1974). Forrest (2013) mentioned that the SOR model might reflect sensor input's assertion from the environment as the stimulus that combines with personality factors and may trigger an organism's internal or primarily emotional reaction. This action subsequently results in behavioural outcomes or known as responses. Some behavioural outcomes, such as the approach behaviours, include the desire to explore, work, and cooperate with others, while avoiding behaviours include retreating, aversion to others, and desire to leave the situation. Mehrabian and Russell's SOR Model (1974) portray personality or individual behaviour that may influence their emotional response. In the context of this study, this is reflected through the service delivery and social servicescape aspects, with several elements that are predicted to influence the NFSL's effectiveness and visitors' response after their visits. Among the elements studied are the employees' behaviours, social density (crowd), and displayed emotion of other visitors that may affect the effectiveness of NFSL and visitor's behavioural responses. The behavioural 
responses in the expanded SOR model by Mehrabian and Russell's (1974) is illustrated in Figure 2.

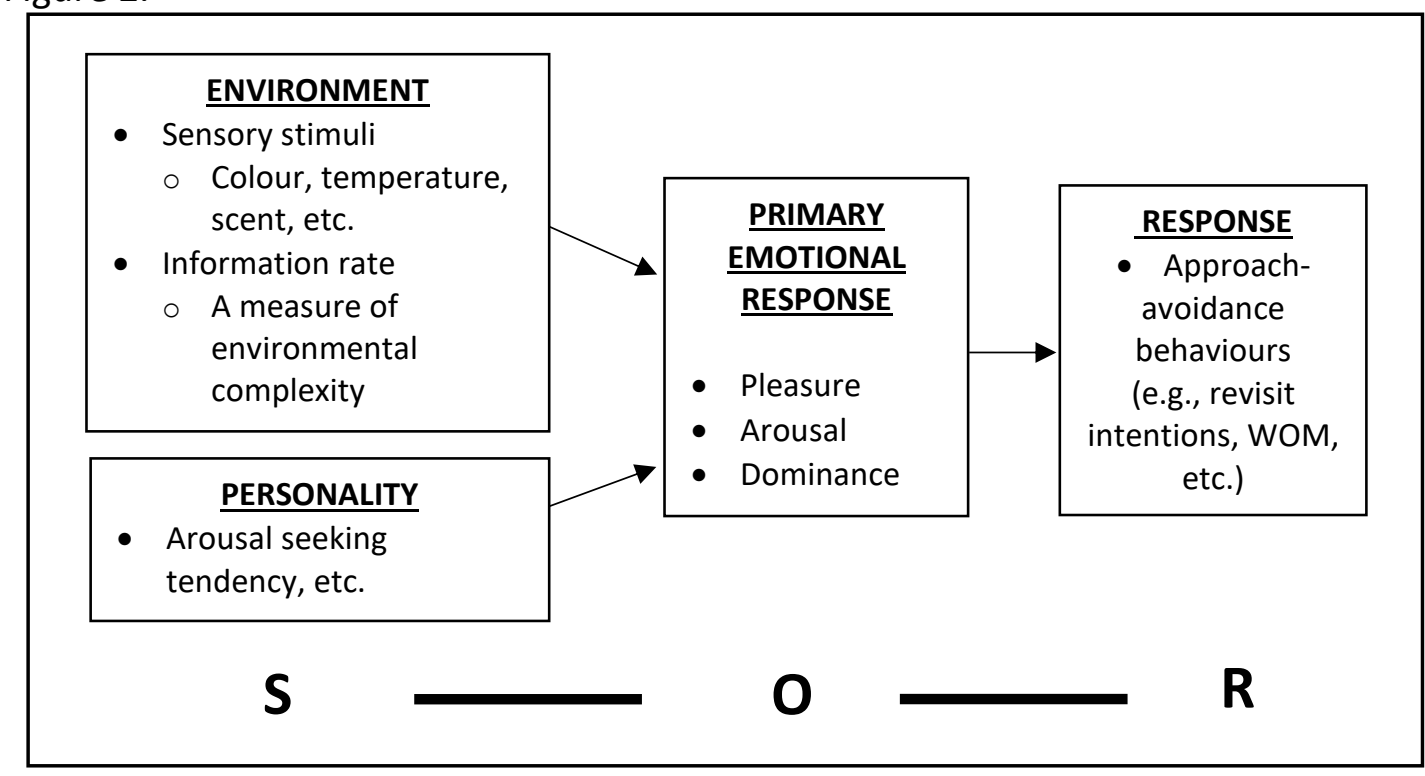

Figure 2

Mehrabean and Russell SOR Model (1974)

Figure 2 explains how the customers and employees (represented by the organisms in the SOR model) behave towards certain variables in the service environment. It resulted in approach-avoidance behaviour as a response through the whole services experience of personality or social stimuli (service delivery and social servicescape) and environmental stimuli (the physical servicescape) within the compounded area. In this study, the primary emotional response is represented by the NFSL's effectiveness in measuring the dynamic elements of pleasure and arousal at the primary emotional stage as the mediator. Lockwood and Pyun (2019) highlighted that the dominance element is less favourable and commonly skipped due to a lack of significant findings to link them with the model, especially towards the approach-avoidance behavioural response. In a study of the SOR model within the retail setting, Donovan and Rossiter (1982) failed to find the link between the dominance dimension and approach-avoidance behavioural responses. Besides, Russell and Pratt (1980) highlighted that pleasure arousal alone could represent the primary emotional state adequately in the SOR model without dominance. Thus, dominance is omitted (representing the mediation phase) in this study due to its insufficient empirical support, as the scholars claimed.

Understanding service experience involving the customers' primary emotional responses is vital to promote an organisation's efficiency and survival, especially for hedonic places associated with fun, pleasure, sensation and excitement (Tubillejas-Andrés et al., 2020; Voorhees et al., 2017), like the science centre. The interaction between the service provider and the visitors is positively related to pleasure and arousal feelings within the hedonic services, which then converts the stimulus exposure into meaningful information for the visitor before deciding to react positively or negatively as a behavioural response (TubillejasAndrés et al., 2020). The pleasure and arousal feelings are the main elements of the visitor's primary emotional stage that represents the NFSL's effectiveness in non-formal learning (NFL) places (Govekar-Okoliš, 2018; Lockwood \& Pyun, 2019; Mujtaba, Lawrence, Oliver, \& Reiss, 2018; Rahma, Sucipto, Ishaq, Raharjo, \& Widyaswari, 2020), such as the science centre. The underpinning SOR model applied in this study is illustrated in Figure 3. 


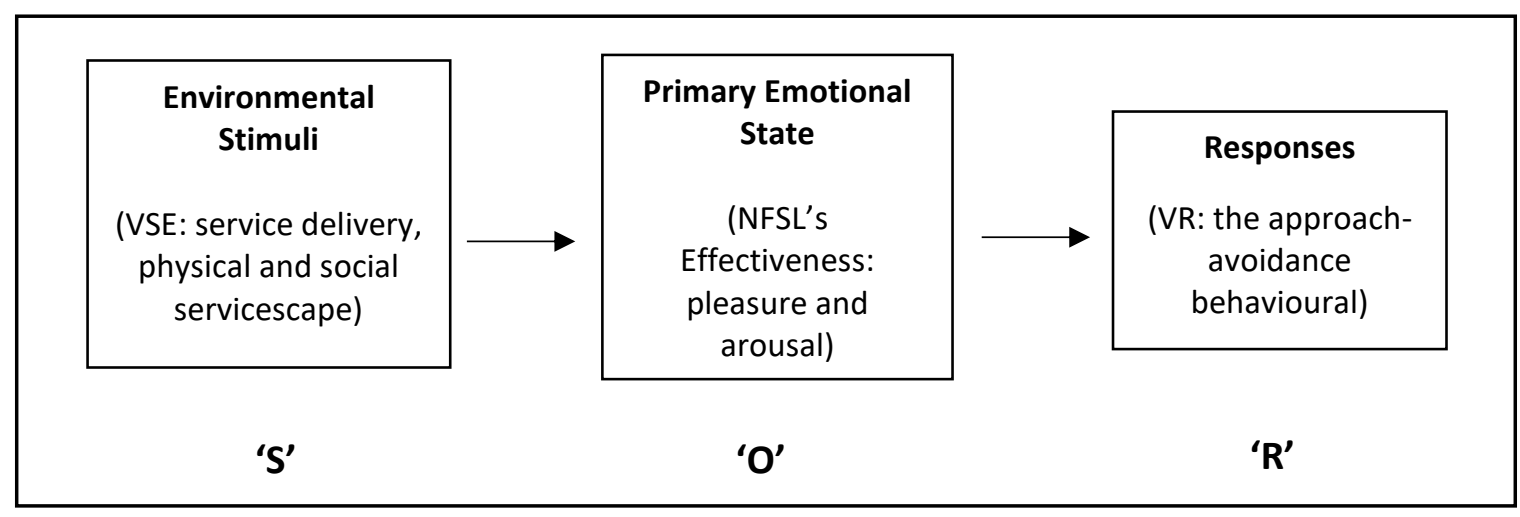

Figure 3

SOR Model Application

As an NFL institution, the science centre's effectiveness is identified as the success of NFSL and its learning outcomes (understanding) in triggering the visitor's primary response feeling (i.e. pleasure and arousal) after the visit. Thus, the NFSL's effectiveness plays its role as a mediator in this study that triggers the visitor's primary emotional stage, resulting in the customer's (or visitor's) psychological outcome (the VR) after consuming the service experience (VSE). The customer (or visitors) always look for positive emotions and are more likely to avoid negative ones (Clark \& Isen, 1982; Tubillejas-Andrés et al., 2020). This means the customers are more likely to avoid situations where the service experiences generate negative emotions in them (Tubillejas-Andrés et al., 2020).

\section{The Research Objectives}

The science centre management has made continuous efforts from time to time to improve the exhibition gallery's contents, exhibition materials, blockbuster exhibitions, and educational programs. However, a lesser effort was invested in addressing the gaps from the social science aspect relating to the holistic VSE perspective (especially for the service delivery, physical, and social servicescape aspects) at the science centre. Thus, several research questions were proposed to enable further investigation of the issues. Among others are: Does the VSE significantly affect VR in the science centre?; Is NFSL mediating the relationships between VSE and VR at the science centre?; and What is the most influencing factor within the VSE that affects the NFSL and the VR in the science centre? The primary purpose of this study is to examine the mediating role of non-formal science learning (NFSL) between the visitor's service experience (VSE) and the visitor's response (VR) at the science centre. With that, this study intends to: 1 ) examine the VSE's factors that are significantly affecting the VR at the science centre; 2 ) analyse the mediating role of NFSL between the VSE and VR at the science centre; and 3) identify the most influencing factors within the VSE that affect the NFSL and VR at the science centre.

\section{Deductive Approach}

In dissecting the issues, the deductive approach uses the existing theory as a device to develop the research framework, organise and design the strategy for data analysis (Saunders et al., 2009), and hypotheses testing (Bryman \& Bell, 2011). This approach aims to explain the variables' relationship by collecting quantitative data from a large sample and deducing generalisation (Saunders et al., 2009). This study's deductive approach was chosen due to its advantages in commencing the research work from guiding theoretical 
perspectives. The appropriate theories help to link the investigation to the existing body of knowledge in the subject area. In this study, the underpinning theories of Environmental Physiological Theory, Service Experience (SE) conceptual model by Chang and Huang (2014), and other supported resources helped provide the initial analytical framework. Saunders et al. (2009) and Yin (2003) mentioned that in developing a descriptive framework, the main variables, components, themes, and issues should be identified first, followed by the presumed relationships. In doing so, the framework is developed based on the mixture of theories and the researcher's experience, or the theories and the observed expectations (Saunders et al., 2009; Yin, 2003). The framework then becomes the primary reference to direct the research's investigation and analysis of data.

\section{The Conceptual Framework}

This study assesses the VSE based on the NSC's service delivery, physical and social servicescape aspects. Previous studies related to the place of attractions, including the science centre and museum, have highlighted the role of service quality in determining visitors' satisfaction and the services' effectiveness; however, they did not pay equal attention to another critical factor, the service experience (Dong \& Siu, 2013). Researchers in services generally defined service experience as "all aspects of the delivery, production and value creation that are considered important from the customer's perspective" (Dong \& Siu, 2013; Ostrom et al., 2010). Thus, in measuring the service experience, the service delivery and servicescapes (physical and social) aspects become the main factors studied to get a holistic picture of the VSE in affecting the VR through the mediating role of NFSL.

As the NSC is a public institution, this study's service delivery factor is derived from a public institution perspective, where the main components are related to people's centricity details, especially the crucial elements of timeliness, accessibility, fair treatment, and outcomes of the services (Daniels, 2013; Public Sector Research Centre, 2007). Other than these, the education (exhibition) outcomes and communication also become part of the essential components of service delivery elements within the science centre or museum setting (Gilmore \& Rentschler, 2002; Hong, Choi, \& Chae, 2020). From the exhibition outcome perspective, the exhibitions' quality is one of the significant factors influencing the NSC's success. Thus, evaluations on the functionality, engagement, finishing, technology infusion and other characteristics of the excellent exhibition were also carried out in this study (Boon, 2014; Markovic et al., 2013; Mey \& Mohamed, 2010; Ng, Wee, Hoo, Suai, \& Moses, 2013; Putra, 2016).

The physical servicescape focuses on the ambient condition, layout $\&$ design, and sign $\&$ symbol in the premise (involving both indoor and outdoor environments). The survey also measured the physical condition of the landscape and outdoor facilities, including the outdoor exhibits and equipment provided at the science centre, potentially influencing the NFSL's effectiveness and the VR at the science centre. Learning within a non-formal learning environment is more expansive than a classroom setting; it includes the visitors' interaction at the outdoor and landscape areas. In contrast, social servicescape focuses on the interaction between the employees and the customers (or visitors), which resembles the social or human element in delivering the services. Another aspect measured within the social servicescape is the social density, which refers to the crowd or tolerance towards the maximum number of people that the visitors can tolerate at one particular time. The last element measured was others' displayed emotion (from the perspective of perceived demographic and psychographic similarity), which helps understand its effect on visitors' 
learning effectiveness and behavioural responses at the science centre. It was predicted in other studies, especially in the retail and leisure industries, that people with similar demographics and psychographic characteristics may influence each other's perceived experiences and approach-avoidance behaviours. Thus, this study investigates the influence of these factors on the effectiveness of NFSL and VR at the end of the visitation.

The NFSL, from its effectiveness aspect, becomes the primary emotional response (mediator) in this study, which influences the VR after visiting the NSC. The visitor's experience is derived from the customer's point of view of the services that affect their learning process at the science centre. The NFSL's effectiveness focused on the pleasure and arousal response that visitors experience from the services offered, omitting the dominance elements. Lockwood and Pyun (2019) highlighted the less favourable usage of the dominant state in the SOR theory-model due to the lack of significant findings that link the dominance state to the behavioural response. Thus, it is not included in this study. The pleasure and arousal experience element assesses the visitor's intrinsic feeling during the visit. The assessment consists of whether the visitor had a happy experience or not, gaining a sense of excitement from the educational visit (Govekar-Okoliš, 2018), including the fun, pleasure, leisure, and escapism elements acquired from the visit (Sheng \& Chen, 2012; Siu, Zhang, Dong, \& Kwan, 2013). To understand all these factors, the Independent Variables (IVs) and Dependent Variable (DV) in this study are featured in the Conceptual Framework in Figure 4.

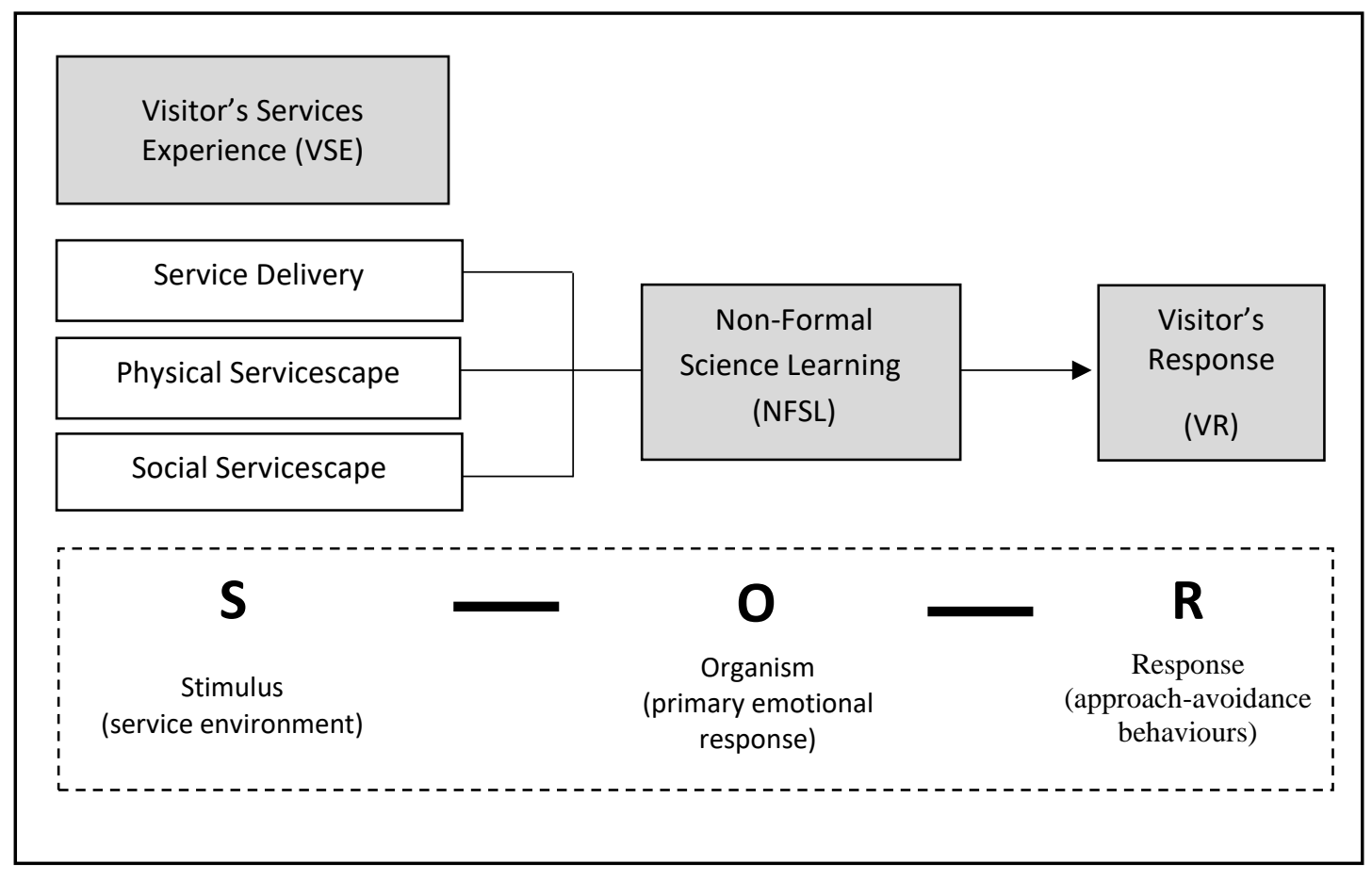

Figure 4

The Conceptual Framework

Figure 4 explained the conceptual framework that describes the study's intention to test the effects of VSE (the IVs) on the VR (as the DV) with the mediating role of NFSL. The VR as the endogenous construct in this study becomes the final attribute that measures the visit experience's outcomes, assessing the emergence of either positive or negative approachavoidance behaviours at the end of the visit. The VR is derived from the behaviour of the visitors after experiencing the visit to the NSC. The visitor's behavioural response relates 
closely with approach-avoidance behaviours such as the prolong of a visit, intention to stay, intention to revisit, intention to purchase, and the spread of word-of-mouth (WOM).

\section{Conclusion}

In its effort to tackle the main issues of visitation rate, revenue generation, and a better organisational image in a public science centre, this study investigates the social science aspects of the services, which related closely to the visitor's centricity element; the visitor's service experience. This study started the investigation by understanding the potential factors that theoretically cause the approach-avoidance behaviours of a visitor in the service experience domain within the science centre setting. As suggested by Saunders et al. (2009), the deductive approach uses the existing theory as a device to develop the research framework, organise and design the strategy for data analysis. Thus the approach does help in identifying the possible dimensions or factors that theoretically causes the problems and outline the most plausible framework that suits the main issues.

The service experience framework has been used widely in the service industries, with the well-known SOR theory-model guides the researchers to predict the stimulus or dimensions that potentially affect the customers' behavioural response. With the quantitative research in mind, referring the main issues to the underpinning theory increase the possibility of finding the potential dimensions that causing the problem. Applying the framework with some expansions of the model and theory encourages further understanding of how people respond to objective stimuli in a spatially bounded consumption setting, such as in the science centre, and finally predicted their approach-avoidance behaviours.

Based on the approaches taken, the underpinning SOR theory-model by Mehrabean and Russel (1974) has guided this study to focus on the customer-centricity element related to the VSE. The VSE stresses its main dimensions, namely the service delivery, the physical and social servicescapes that theoretically affect the visitor's approach-avoidance behaviours. This study aims to examine the effects of VSE on VR with the mediating role of NFSL in the science centre. The VR results from the visitors' approach-avoidance behavioural response after exposure to the VSE's factors as the stimulus in the science centre setting. With the justified framework in place, the research is positioned to proceed with other steps, including data collection and statistical analysis for reliability and validation measures.

The government has empowered NSC as the centre of excellence for STIE and has given them a solid mandate to deliver effective enculturation STI programs amongst Malaysians. Thus, this study's findings suggest a framework that may potentially help them to execute such policies, specifically for the STI enculturation and popularisation efforts through public science centres like the NSC. It is hoped that the centre will attract new and repeated visitors and retain their loyalties by doing so. On top of that, the centre may also benefit from gaining better revenue generation, developing a more positive institutional image, reducing complaints against its premise, and most importantly, improving the level of satisfaction among its visitors. This situation could potentially help maintain the sustainability and competitiveness of the NFSL institutions, especially for institutions within the public sector, such as the NSC.

\section{References}

Barker, R. G. (1968). Ecological Psychology: Concepts and Methods for Studying the Environment and Human Behavior. (Kansas University, Ed.). California: Stanford University Press. 
Boon, N. S. (2014). Science Education : Challenges and the Way Forward. Ministry of Education Malaysia, 1-61. Retrieved from http://research.utar.edu.my/SoSE2014/1.Challenges and issues in science education.pdf

Bryman, A., \& Bell, E. (2015). Business Research Methods (4th ed.). Cambridge, New York: Oxford University Press.

Chang, W. L., \& Huang, L. Y. (2014). Measuring Service Experience: A Utility-Based Heuristic Model. Service Business, 10(1), 1-30. https://doi.org/10.1007/s11628-014-0263-9

Clark, M. S., \& Isen, A. M. (1982). Toward Understanding the Relationship Between Feeling States and Social Behavior. (A. Hastorf \& A. Isen, Eds.), Cognitive Social Psychology. New York: Elselvier North-Holland.

Daniels, A. (2013). Quality in Public Service Delivery. Regional Hub of Civil Service's EJournal, 55-64.

Dong, P., \& Siu, N. Y. M. (2013). Servicescape Elements, Customer Predispositions and Service Experience: The Case of Theme Park Visitors. Tourism Management, 36, 541551. https://doi.org/10.1016/j.tourman.2012.09.004

Donovan, R. J., \& Rossiter, J. R. (1982). Store Atmosphere: An Environmental Psycology Approach. Journal of Retailing, 58(1), 34-57.

Falk, J. H., \& Needham, M. D. (2011). Measuring the Impact of a Science Center on Its Community. Journal of Research in Science Teaching, 48(1), 1-12. https://doi.org/10.1002/tea.20394

Falk, John H., Needham, M. D., Dierking, L. D., \& Prendergast, L. (2014). Final Report: International Science Centre Impact Study. OR USA.

Forrest, R. (2013). Museum Atmospherics: The Role of the Exhibition Environment in the Visitor Experience. Visitor Studies, 16(2), 201-216. https://doi.org/10.1080/10645578.2013.827023

Gilmore, A., \& Rentschler, R. (2002). Changes in Museum Management: A Custodial or Marketing Emphasis? Journal of Management Development, 21(10), 745-760. https://doi.org/10.1108/02621710210448020

Govekar-Okoliš, M. (2018). Effectiveness of School Lessons From the Past as Living Forms of Museum Education for University Students. Museum Management and Curatorship, O(0), 1-16. https://doi.org/10.1080/09647775.2018.1490198

Hong, S. J., Choi, D., \& Chae, J. (2020). Exploring Different Airport Users' Service Quality Satisfaction Between Service Providers and Air Travelers. Journal of Retailing and Consumer Services, 52(July 2019), 101917. https://doi.org/10.1016/j.jretconser.2019.101917

Hyun, H., Park, J., Ren, T., \& Kim, H. (2018). The Role of Ambiances and Aesthetics on Millennials' Museum Visiting Behavior. Arts and the Market, 8(2), 152-167. https://doi.org/10.1108/aam-04-2017-0006

Lockwood, A., \& Pyun, K. (2019). How Do Customers Respond to the Hotel Servicescape? International Journal of Hospitality Management, 82(March), 231-241. https://doi.org/10.1016/j.ijhm.2019.04.016

Loureiro, S. M. C. (2015). Medical Tourists' Emotional and Cognitive Response to Credibility and Servicescape. Current Issues in Tourism, 20(15), 1633-1652. https://doi.org/10.1080/13683500.2015.1050363

Markovic, S., Raspor, S., \& Komšic, J. (2013). Museum Service Quality Measurement Using the Histoqual Model. Tourism in Southern and Eastern Europe, 497(5), 201-216. 
Mehrabean, A., \& Russell, J. A. (1974). An Approach to Environmental Psychology. Cambridge. MA: US: The MIT Press.

Mey, L. P., \& Mohamed, B. (2010). Service Quality, Visitor Satisfaction and Behavioural Intentions : Pilot Study At a Museum in Malaysia. Journal of Global Business and Economics, 1(1), 226-240.

MOSTI. (2020). Dasar Sains, Teknologi, dan Inovasi Negara 2021-2030. Putrajaya. Retrieved from https://www.mosti.gov.my/web/dasar-halatuju/

Mujtaba, T., Lawrence, M., Oliver, M., \& Reiss, M. J. (2018). Learning and Engagement Through Natural History Museums. Studies in Science Education, 54(1), 41-67. https://doi.org/10.1080/03057267.2018.1442820

Ng, D. V., Wee, G., Hoo, L., Suai, W., \& Moses, A. (2013). Design of Interactive Multimedia Display Application for Sarawak Museum based on Visitors ' Preferences. Journal of Advanced Computer Science and Technology Research, 3(1), 39-50.

Ostrom, A. L., Bitner, M. J., Brown, S. W., Burkhard, K. A., Goul, M., Smith-Daniels, V., ... Rabinovich, E. (2010). Moving Forward and Making a Difference: Research Priorities for the Science of Service. Journal of Service Research, 13(1), 4-36. https://doi.org/10.1177/1094670509357611

Parker, L. C., \& Krockover, G. H. (2013). Science Education for Diversity and Informal Learning. In M. N. \& R. Wegerif (Eds.), Science Education for Diversity: Theory \& Practice (Vol.8, pp. 79-96). Exeter, UK: Springer, Dordrecht. https://doi.org/10.1002/sce.20220.CrossRefGoogle

Public Sector Research Centre. (2007). The Road Ahead for Public Service Delivery Delivering on the Customer Promise. Public Sector Research Centre. The UK. Retrieved from www.psrc-pwc.com

Putra, F. (2016). Implementation of HISTOQUAL Model to Measure Visitors' Expectations and Perceptions in Museum Geology Bandung. In Proceedings of the Asia Tourism Forum. 2016 - the 12th Biennial Conference of Hospitality and Tourism Industry in Asia (pp. 0-103). https://doi.org/10.2991/atf-16.2016.48

Rahma, R. A., Sucipto, Ishaq, M., Raharjo, K. M., \& Widyaswari, M. (2020). The Effectiveness of Augmented Reality-Based Board Game as Learning Media in Comprehending Family Functions Concept. Proceedings - 2020 6th International Conference on Education and Technology, ICET 2020, 102-108. https://doi.org/10.1109/ICET51153.2020.9276584

Rosenbaum, M. S., \& Massiah, C. (2011). An Expanded Servicescape Perspective. Journal of Service Management, 22(4), 471-490. https://doi.org/10.1108/09564231111155088

Russell, J. A., \& Pratt, G. (1980). A Description of the Affective Quality Attributed to Environments. Journal of Personality and Social Psychology, 38(2), 311-322.

Saunders, M., Lewis, P., \& Thornhill, A. (2009). Research Methods for Business Students (5th ed.). Essex, UK: Pearson Education Limited. https://doi.org/10.1017/СBO9781107415324.004

Sheng, C. W., \& Chen, M. C. (2012). A Study of Experience Expectations of Museum Visitors. Tourism Management, 33(1), 53-60. https://doi.org/10.1016/j.tourman.2011.01.023

Siu, N. Y. M., Zhang, T. J. F., Dong, P., \& Kwan, H. Y. (2013). New Service Bonds and Customer Value in Customer Relationship Management: The Case of Museum Visitors. Tourism Management, 36, 293-303. https://doi.org/10.1016/j.tourman.2012.12.001

Tubillejas-Andrés, B., Cervera-Taulet, A., \& Calderón García, H. (2020). How Emotional Response Mediates Servicescape Impact on Post Consumption Outcomes: An Application to Opera Events. Tourism Management Perspectives, 34(100660), 1-13. 
INTERNATIONAL JOURNAL OF ACADEMIC RESEARCH IN BUSINESS AND SOCIAL SCIENCES Vol. 11, No. 6, 2021, E-ISSN: 2222-6990 @ 2021 HRMARS

https://doi.org/10.1016/j.tmp.2020.100660

Voorhees, C. M., Fombelle, P. W., Gregoire, Y., Bone, S., Gustafsson, A., Sousa, R., \& Walkowiak, T. (2017). Service Encounters, Experiences and the Customer Journey: Defining the Field and a Call to Expand Our Lens. Journal of Business Research, 79(April), 269-280. https://doi.org/10.1016/j.jbusres.2017.04.014

Yin, R. K. (2003). Case Study Research: Design and Methods (3rd ed.). Thousand Oaks, CA: SAGE Publications. Inc. 